\title{
A poética do jogo no romance O mestre, de Ana Hatherly
}

\author{
Claudio Alexandre de Barros Teixeira \\ Universidade de São Paulo
}

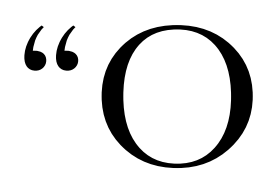

jogo não é compreendido pela antítese entre sabedoria e loucura, ou pelas que opõem a verdade e a falsidade, ou o bem e o mal. Embora seja uma atividade material, não desempenha uma função moral, sendo impossível aplicar-lhe as noções de vício e virtude". ${ }^{1}$ Por estar além das dicotomias habituais da ética e da metafísica e assumir "acentuados elementos de beleza", o jogo está próximo da estética. Estas formulações de Huizinga guardam um forte paralelo com o texto inicial do romance $O$ mestre, de Ana Hatherly: "A Mentira é recriação de uma Verdade. O mentiroso cria e recria. Ou recreia. A fronteira entre estas duas palavras é tênue e delicada. Mas as fronteiras entre as palavras são todas tênues e delicadas. Entre a recriação e o recreio assenta todo o jogo". ${ }^{2}$ Nesta passagem programática, além de relativizar as noções de verdadeiro e falso - tema aliás abordado na Tisana $298^{3}$-, a autora brinca com as diferentes acepções da palavra jogo, entre elas a de "recreio" (que no dicionário de Aurélio Buarque de Hollanda aparece como "brinquedo", "passatempo" e "divertimento"), num tom irônico e ardiloso que aponta para outras definições de jogo, como "escárnio, ludíbrio" e "manha, astúcia, ardil”. 4 A palavra "recrio" também é estratégica, pois indica o engenho inventivo da autora, que se propôs a escrever um romance que em nada se

\footnotetext{
${ }^{1}$ HUIZINGA, 2007, p. 9.

${ }^{2}$ HATHERLY, 2006a, p. 21.

3 "Era uma vez uma verdade que era defendida pelos inimigos da verdade os quais defendiam a sua desonra. Eram espantosamente certeiros no errado, mas isso acontece muito." (HATHERLY, 2006b, p. 116).

${ }^{4}$ HOLLANDA, 1986, p. 990.
} 
parece com a tradição clássica do gênero, situado fora das dimensões narrativas tradicionais e com peripécias que se resumem a breves diálogos e poucas ações. $\mathrm{O}$ jogo entre recriação e recreio tramado nesta obra "rompe com as fronteiras estabelecidas entre a narrativa e a poesia", ${ }^{5}$ como diz Nadiá Paulo Ferreira, inserindo-se, portanto, na mesma zona híbrida e miscigenada de Anacrusa e das Tisanas: não se trata de prosa poética ou romance em versos, mas sim de texto inventivo, experimental, que despreza os limites entre os gêneros. Conforme observou Maria Alzira Seixo na segunda ediçãa portuguesa de $O$ mestre, há nessa obra "um grande afastamento em relação à definição das estruturas romanescas consideradas normais (tempo, personagens, espaço, intriga)", ${ }^{6}$ o que diferencia este livro da "tradição do romance oitocentista que se prolonga (...) pelas primeiras décadas do século XX afora, tanto na Presença quanto no Neo-Realismo", 7 como escreveu José Carlos Barcello na contracapa da edição brasileira. "Ana Hatherly não escreveu este livro como se Virgínia Woolf e James Joyce nunca tivessem existido. Escreveu a partir do seu legado, sem deixar de se associar à efervescência experimental dos anos 60", segundo Silvina Rodrigues Lopes, em seu prefácio à terceira edição portuguesa do romance. ${ }^{8}$ Ao contrário das narrativas ficcionais de cunho linear, em $O$ mestre "as personagens não têm nome próprio. ${ }^{9}$ As palavras que têm como função substituir o nome próprio apontam para o lugar que as personagens ocupam em uma história de amor", ${ }^{10}$ diz Nadiá Paulo Ferreira. Em vez de nomes, o romance traz epítetos para os personagens: assim, temos "uma Discípula que procura obstinadamente um Mestre para amar e ser amada, o que lhe permitiria (...) 'atingir a Alegria”, ${ }^{11}$ e um Mestre "cuja principal característica é o riso". ${ }^{12}$ "Mestre e discípulo são

${ }^{5}$ HATHERLY, 2006a, p. 14.

${ }^{6}$ HATHERLY, 1976, p. 10.

${ }^{7}$ HATHERLY, 2006 a.

${ }^{8}$ HATHERLY, 1995, p 8.

${ }^{9} \mathrm{Nas}$ Tisanas, o personagem-narrador também não é nomeado; apenas o porco de estimação Rosalina possui um nome.

${ }^{10}$ HATHERLY, 2006a, p. 13.

${ }^{11}$ HATHERLY, 2006a, p. 14.

${ }^{12}$ HATHERLY, 2006a, p. 15. 
conceitos fundamentais envolvidos no processo pedagógico que visa a transmissão e renovação de conhecimento", 13 escreve Silvina Rodrigues Lopes. "Os Mestres vêm do Oriente", prossegue a autora, "confundindo-se com os enigmas das suas falas; são, como Sócrates, exemplares e irônicos (...). Por um movimento de abstractização, o Mestre torna-se todos os mestres", ${ }^{14}$ assim como "a Discípula, que é todos os discípulos". ${ }^{15}$ Ela "representa a capacidade de pergunta e de questionação, a perseguição de uma finalidade que aqui se chama amor ou ciência”, ${ }^{16}$ conforme Maria Alzira Seixo. Temos aqui tipos dramáticos, portanto, como no teatro vicentino: ${ }^{17}$ o Mestre, com um perfil de monge zen ou sábio taoísta, que prefere o riso, o silêncio ou sentenças enigmáticas a um ensinamento direto da verdade (assim como nos koans budistas, parodiados nas Tisanas); e uma Discípula ávida pelo saber, que para ela é o mesmo que o amor e a alegria (numa palavra: a plenitude). Este livro desconcertante, narrado ora na terceira pessoa, ora na primeira (como as Tisanas), é, paradoxalmente, um ensaio sobre o amor, ou ainda sobre a impossibilidade do amor, um dos temas básicos de Ana Hatherly, sintetizado na Tisana 285: "O verdadeiro amor é um ato indisponível". ${ }^{18}$ Conforme Nadiá Paulo Ferreira, " $O$ mestre se insere de forma bastante original na tradição do mito de amor das literaturas em língua portuguesa", ${ }^{19}$ embora sem os "artifícios românticos que velam o amor impossível". ${ }^{20}$ A originalidade da autora, diz Nadiá Paulo Ferreira, está na "conjugação entre amor e saber, sendo que este último se torna condição para a descoberta do amor e sua verdade". ${ }^{21}$

${ }^{13}$ HATHERLY, 1995, p. 11.

${ }^{14}$ HATHERLY, 1995, p. 11.

${ }^{15}$ HATHERLY, 1995, p. 11.

${ }^{16}$ HATHERLY, 1976, p. 14.

${ }^{17}$ Conforme Ana Hatherly: "O Mestre é um personagem porque é uma pessoa e na origem da pessoa está a máscara. Além disso o Mestre usa máscara, tem máscara, é máscara. Um dos aspectos da sua máscara (ou da sua pessoa) é ser Mestre - usa a máscara de Mestre." (HATHERLY, 2006a, p. 22)

${ }^{18}$ HATHERLY, 2006b, p. 113.

${ }^{19}$ HATHERLY, 2006a, p. 13.

${ }^{20}$ HATHERLY, 2006a, p. 13.

${ }^{21}$ HATHERLY, 2006a, p. 14. 
O vínculo pedagógico ${ }^{22}$ e de sedução entre Mestre e Discípula é justamente o eixo narrativo do livro, cuja estrutura é similar à de um jogo. ${ }^{23}$

"Começando pelos elementos constitutivos, deparamos com uma introdução em que um narrador apresenta uma espécie de programa teórico relativo ao conhecimento (...) e uma experiência particular que é a relação (...) entre um Mestre e uma Discípula”, ${ }^{24}$ escreve Maria Alzira Seixo. Após essa abertura programática, o romance apresenta "dez capítulos, divididos em parágrafos, em que o Mestre e a Discípula se perseguem, tentando comunicar e atingir a ciência". ${ }^{25}$ Temos aqui a definição do espaço estrutural em que acontece o jogo, a apresentação dos jogadores e ainda uma breve descrição de suas jogadas. A Discípula anseia obter o amor do Mestre, e todas as ações que desenvolve ao longo do romance são executadas neste sentido; logo, este é o objetivo do jogo. Se ela for vencedora, obterá "a Alegria plena e perfeita, como metáfora da aspiração amorosa”; ${ }^{26}$ se for derrotada, poderá recolher resultado inauspicioso, pois, como adverte o Mestre, "há coisas que a gente não deve querer", ${ }^{27}$ este, para ela, é o risco do jogo. Os lances da partida transcorrem em dois cenários básicos, a sala de visitas da casa do Mestre, onde a Discípula vai visitá-lo, e um jardim onde ela tenta simular encontros casuais (lugar simbólico que remete, possivelmente, ao jardim do Éden, com a árvore do conhecimento do bem e do mal, aos labirintos vegetais, ${ }^{28}$

${ }^{22}$ Segundo Johan Huizinga, a palavra japonesa asobu significa "estudo sob a direção de um professor ou numa universidade, o que nos faz lembrar o uso da palavra latina ludus no sentido de escola”. Em japonês e em latim, aprender junto a um professor é uma forma de jogo.

${ }^{23}$ Silvina Rodrigues Lopes aponta, no romance de Ana Hatherly, o "jogo lúdico que é tanto o jogo de palavras como a criação de cenas informadas pelos princípios da anamorfose. Reflexão e jogo coincidem desde a apresentação das personagens enquanto tais, que alarga a interrogação da representação à dos próprios limites entre o ficcional e o não-ficcional, até a própria relação entre personagens e conceitos". (HATHERLY, 1995, p. 11)

${ }^{24}$ HATHERLY, 1976, p. 13.

${ }^{25}$ HATHERLY, 1976, p. 13.

${ }^{26}$ HATHERLY, 2006a, p. 15.

${ }^{27}$ HATHERLY, 2006a, p. 22.

${ }^{28}$ Os labirintos eram construções edificadas geralmente em pedra, mas também havia "labirintos vegetais, inseridos nos jardins, igualmente com todas as suas implicaçōes lúdicas", conforme escreveu Ana Hatherly em A Experiência do Prodígio (HATHERLY, 1983, p. 83). 
ao jardim de Belisa e Don Perlimplin, na peça de Lorca, e ainda ao Parque Eduardo VII, em Lisboa). As tentativas de sedução da Discípula, como observa Nadiá Paulo Ferreira, colocam em cena "a estrutura da paixão: o amante suplica ser correspondido e exige ser amado do modo que ele imagina que se deve amar". ${ }^{29}$ Seguindo uma regra do jogo amoroso, "a Discípula se oferece amável para o Mestre, seduzindo-o, porque o que ela deseja é ser a preferida do seu Mestre. Ou seja: entregar-se ao Mestre e em troca tê-lo no regime de exclusividade". ${ }^{30}$ Essa trama, tradicional na literatura de amor, por si só constitui um jogo; conforme Huizinga, "Aquilo que o espírito da linguagem tende a conceber como jogo não é propriamente o ato sexual enquanto tal, trata-se principalmente do caminho que a ele conduz, o prelúdio e preparação do amor, que frequentemente revela numerosas características lúdicas". ${ }^{31}$ Entre os "elementos dinâmicos do jogo" inerentes ao processo da sedução encontram-se "a criação deliberada de obstáculos, o adorno, a surpresa, o fingimento, a tensão etc.", ${ }^{32}$ que podemos identificar em diversas passagens, ao longo da leitura do romance, como por exemplo, na primeira visita da Discípula à casa do Mestre, em que este cria dificuldades para recebê-la.

Segundo Huizinga, a compreensão do amor como um tipo de jogo é "especialmente, ou mesmo exclusivamente, reservada para as relações eróticas que escapam à norma social", ${ }^{33}$ conceito que ilustramos com o mito de Tristão e Isolda, estudado por Denis de Rougemont em História do Amor no Ocidente, além de toda a literatura derivada da tradição trovadoresca, até o romantismo do século XIX e mesmo nos dias atuais. No caso de $O$ mestre, essa ruptura com a "norma social" não está num triângulo amoroso ou adultério, nem mesmo na assimetria de faixa etária ou posição social, mas na impossibilidade física da união erótica, já que o Mestre é homossexual, logo, incapaz de corresponder às expectativas da Discípula. A dissociação entre eles é marcada também por expressivas diferenças de personalidade: o Mestre que sempre

\footnotetext{
${ }^{29}$ HATHERLY, 1983, p. 15.

${ }^{30}$ HATHERLY, 1983, p. 15.

${ }^{31}$ HUIZINGA, 2007, p. 49.

${ }^{32}$ HUIZINGA, 2007, p. 49-50.

${ }^{33}$ HUIZINGA, 2007, p. 49-50.
} 
ri é "cheio de contradiçôes", ${ }^{34}$ "perito na arte de simular", 35 "não sente", 36 está "sempre a mentir", 37 "troça de tudo", 38 é um "anjo indeciso", 39 comparável a um "muro". ${ }^{40}$ A Discípula, por sua vez, "não gostava de rir nem tampouco de chorar e é por isso que andava à procura da Alegria, já que essa devia excluir o riso e o choro"; 41 ela "tem a mania do encontro das almas" e ainda "a mania do conhecimento, da aprendizagem, é curiosa, ávida, inquisidora, persistente". ${ }^{42}$ A comunicação entre eles sempre ocorre na fronteira da incomunicabilidade: nas reuniōes lúdicas realizadas no jardim ou na casa do Mestre, os diálogos entre o Mestre e a Discípula são concisos, desencontrados, enigmáticos, quase antagônicos, num conflito ou tensão que evidencia a distância, mais do que o encontro entre aquela que ama e aquele que recusa ser amado. Conforme escreve Maria Alzira Seixa, a "perseguição" do Mestre pela Discípula "consiste num jogo de contatos de matiz deceptivo", numa troca de "falas com o mesmo grau de desorientação e intangibilidade (...). Daí que se fale muito, neste texto (falas curtas, incisivas, pouco discursivas), e que não se entenda nada". ${ }^{43}$ Por vezes, o diálogo entre eles assemelha-se ao teatro de Ionesco, ou ainda aos mondos (diálogos construídos como sucessão de enigmas) dos contos tradicionais zen-budistas, em mais um ponto de contato com as Tisanas, como nesta passagem do oitavo capítulo do romance:

${ }^{34}$ HATHERLY, 2006a, p. 29.

${ }^{35}$ HATHERLY, 2006a, p. 30.

${ }^{36}$ HATHERLY, 2006a, p. 35.

${ }^{37}$ HATHERLY, 2006a, p. 35.

${ }^{38}$ HATHERLY, 2006a, p. 45.

${ }^{39}$ HATHERLY, 2006a, p. 81.

${ }^{40}$ HATHERLY, 2006a, p. 81.

${ }^{41}$ HATHERLY, 2006a, p. 22.

${ }^{42}$ HATHERLY, 2006a, p. 32.

${ }^{43}$ HATHERLY, 1976, p. 13. O tema da incomunicabilidade é outra chave temática comum a esta obra e às Tisanas, onde lemos, na composição de n. 49: "Estou aqui e contemplo o suicídio dos objetos habituais. Na mutilação da própria cadeira em que me sento vejo a morte lenta e saturada que consiste na imolação pela comunicação" (HATHERLY, 2006b, p. 44). 
- Então não há esperança de a gente se entender...

- Sim, deve haver, mas não sei bem como. Talvez fechando os olhos e passando a ouvir com os lábios.

- O quê? Descer aos sentidos?

- Quem é que falou em descer ou subir?

- Costuma-se dizer...

- O que é costume aqui não vale nada. É preciso ver tudo a uma nova luz.

- Que luz?

- A luz das trevas.

- Desisto.

- Então ficarás eternamente cego. ${ }^{44}$

O diálogo entre Mestre e Discípula é lúdico: não comunica uma mensagem unívoca, embora opaca, mas dissimula, oculta, deforma ou confunde o sentido, para além das dicotomias entre verdade e mentira, e portanto fora da esfera de recepção de qualquer tipo de conhecimento. "A comunicação (aprendizagem) revela-se deste modo impossível; a única progressão realizada no texto é exatamente a descoberta dessa impossibilidade", ${ }^{45}$ escreve Maria Alzira Seixo. O jogo da dissimulação e ocultamento manifesta-se sobretudo na peripécia que transcorre nos episódios do jardim, em que a Discípula persegue furtivamente o Mestre para simular um encontro casual, e ele esquiva-se fingindo ignorar a perseguição, num jogo de avanços e recuos estratégicos, como os movimentos das pedras em um tabuleiro de xadrez. Há um pacto lúdico entre eles, para usarmos uma expressão formulada por Affonso Ávila em seu estudo sobre o jogo no universo barroco. ${ }^{46}$ A própria narradora no romance define o jardim como "um lugar de jogo. Pequeno jogo de roda, pequeno duelo ao longe, pequeno torneio futuro, morte dos jogadores, começo de outro jogo, fim de outro jogo etc. nunca mais acaba". ${ }^{47} \mathrm{O}$ espaço dessa aparente brincadeira de esconde-esconde é comparado a um círculo mágico, imagem metafórica que sugere a idéia de

\footnotetext{
${ }^{44}$ HATHERLY, 2006b, p. 89.

${ }^{46}$ ÁVILA, 1994, p. 64.

${ }^{47}$ ÁVILA, 1994, p. 79.
} 
labirinto: ${ }^{48}$ "A Discípula é muito persistente. Vai todos os dias ao Jardim a ver se o fruto já está maduro. Sai calmamente de fora do círculo mágico para dentro do círculo mágico. Entra no Jardim. Começa olhando agudamente para todos os lados. Desce à direita o desenho grego da calçada e vai até ao fim". ${ }^{49}$ Os movimentos da Discípula nesse campo simbólico recordam a perambulação do peregrino dentro de um labirinto barroco, onde ele teria de enfrentar "os perigos e as dificuldades de percurso" para "atingir a Jerusalém celeste, a cidade de Deus, ou seja, a união com Cristo”, conforme escreveu Ana Hatherly em seu estudo A experiência do prodígio - Bases teóricas $e$ antologia de textos-visuais portugueses dos séculos XVII e XVIII. ${ }^{50}$ Essa perambulação tinha um caráter iniciático: em sua jornada mística da periferia até o centro da arquitetura simbólica, o peregrino deveria travar um "confronto consigo próprio através dum combate-percurso cujo objetivo é destruir o mal (se no centro estiver um monstro) ou alcançar a salvação (se no centro estiver a Igreja)" ${ }^{51}$ A Discípula, no início do percurso, encara o Mestre como aquele a quem deseja se entregar, numa união mística (com o sentido de realização e plenitude), como se ele fosse um novo Cristo; num segundo momento, porém, ela o verá como um monstro, o Minotauro a quem é preciso matar (o que causará sua própria destruição), após perceber que o amor entre eles não é realizável, e tampouco a sabedoria ou a alegria. Silvina Rodrigues Lopes observou que "O tema do desencontro amoroso", no romance, "é responsável pela deambulação labiríntica", em cujo desfecho macabro a Discípula "vê a sua cabeça capturada como um dos troféus do Mestre que acabara de matar". ${ }^{52}$ Ao destruir seu objeto de desejo, convertido em inimigo monstruoso, a Discípula realiza uma ação de natureza simbólica ou arquetípica: nas palavras de Maria Alzira Seixo, neste romance "a única

\footnotetext{
${ }^{48} \mathrm{~A}$ imagem do labirinto já estava presente na sala de visitas do mestre, cujo sofá tem "desenhos orientais" que lhe dá um aspecto de "tapete persa antigo" (ÁVILA, 1994, p. 28). A construção geométrica com arabescos da tapeçaria é similar a formas como a mandala tibetana, o yantra hindu e os labirintos ocidentais.

${ }^{49}$ ÁVILA, 1994, p. 77.

${ }^{50}$ HATHERLY, 1983, p. 83.

${ }^{51}$ HATHERLY, 1983, p. 83.

${ }^{52}$ HATHERLY, 1995, p. 10.
} 
ação é a da morte e mesmo essa é a mitológica, o Mestre-minotauro morto por Ariana-a-Discípula, amante da luz e da verdade e por ele também assassinada”. ${ }^{53} \mathrm{~A}$ descrição do crime nas páginas finais do romance é alegórica, paródica e não isenta de certo humor negro: a sala do Mestre é convertida numa "gruta" ou "cripta", que está "toda decorada de pinturas, de retratos de jovens em movimento e em repouso, cândidos e ágeis guerreiros ou poetas ou copeiros do eterno rei Minos", ${ }^{54}$ numa desterritorialização simbólica de tempo e espaço que converte Lisboa na ilha de Creta. A Discípula "aparece agora criselefantina, pronta a dar o salto mortal por cima da cabeça do Mestre"; 55 ela "paramenta-se de oiro mas deixa o peito nu porque não há veste mais preciosa do que a pele" ${ }^{56}$ O local onde o Mestre dorme, por sua vez, está "rodeado de todos os seus troféus: discípulos e discípulos mortos estão acumulados aos seus pés. Troféus de caça de toda espécie e armas, redes, laços, fundas, venenos repousam ao seu lado", ${ }^{57}$ numa crítica simbólica à pedagogia como forma de poder. ${ }^{58} \mathrm{Tal}$ como o Minotauro helênico que devorava as virgens que eram enviadas ritualmente a ele como oferendas, o Mestre se alimentava simbolicamente de seus alunos: "Devorava os discípulos e depois cuspia só aquela grainhazinha deles, quer dizer, aquela mínima porção que não lhe interessava". ${ }^{59}$ A mutação do Mestre em Minotauro e de Lisboa na ilha de Creta desloca a mímese em favor representação alegórica dos eventos, que atinge seu clímax no reflexo especular do assassinato, ou sacrifício ritual: após matar o Mestre com um

${ }^{53}$ HATHERLY, 1976, p. 16.

${ }^{54}$ HATHERLY, 2006a, p. 115.

${ }^{55}$ HATHERLY, 2006a, p. 115.

${ }^{56}$ HATHERLY, 2006a, p. 115.

${ }^{57}$ HATHERLY, 2006a, p. 116.

${ }^{58}$ Maria Alzira Seixo já notara, em $O$ Mestre, uma "sátira do ensino como círculo vicioso. Como entronização da ignorância ou do psitacismo” (HATHERLY, 1976, p. 13); Silvina Rodrigues Lopes, por sua vez, observou que "O aparecer do Mestre (...) instaura a relação do ensino como uma relação exorbitante, dissimétrica, sem denominador comum" (HATHERLY, 1995, p. 10). O próprio Mestre, falando em primeira pessoa no romance, diz: "Procuro incutir-lhes no ânimo a submissão às regras" (HATHERLY, 2006a, p. 57).

${ }^{59}$ HATHERLY, 2006a, p. 55. 
golpe de punhal no coração, a Discípula (que assume ao mesmo tempo o papel de Ariadne e de Teseu) "resolve olhar para trás para ver pela última vez o Mestre", num gesto que recorda o de Orfeu e o da mulher de Lot, e vê a si mesma imolada: o Mestre "segura pelos cabelos a cabeça da Discípula. A cabeça da Discípula está trespassada por um punhal enterrado na fronte até ao punho". ${ }^{60}$ Ao destruir aquele a quem ama, ela destrói ao amor e a si mesma. Conforme Nadiá Paula Ferreira,

O coração como símbolo do amor e a cabeça como símbolo do saber são as causas desse duplo assassinato, em que se alegoriza o percurso do mito do amor na literatura portuguesa, desmistificando o que nele permanece velado, que é a impossibilidade de dois se fazer um. Amante e amado não podem complementar um ao outro, porque o que falta ao amante não é o que o amado tem para lhe oferecer. É na falta constitutiva da subjetividade de todo ser humano que está a origem do amor. Negar isso, no caso da Discípula, ou rir disso, no caso do Mestre, como nos avisa o narrador, "resulta trágico ou do trágico". ${ }^{61}$

O jogo da aniquilação recíproca, último lance de uma partida condenada ao fracasso, é prenunciado por outros episódios macabros, inseridos no romance fora de uma ordem cronológica ou de uma seqüência narrativa linear: as ações transcorrem no livro como os movimentos de um sonho, sem uma lógica mimética, tal como em Anacrusa. Estes episódios registram cenas da metamorfose do desejo de fruição erótica num desejo tanático, que sonha com a imolação de si e do outro: no capítulo IV, por exemplo, a Discípula declara que gostaria de enfiar os dentes do Mestre numa fita para colocar em seu pescoço: "De resto foi sempre aí que eu os trouxe, os dentes dele, cravados na minha garganta. É uma maneira de me estrangular com o seu riso. Não creio que ele jamais tenha tido lábios porque lhe eram desnecessários; do que ele precisou sempre foi de dentes, para morder e para rir". ${ }^{62}$ O Mestre é retratado como um gourmet antropófago, "muito voraz", que "devorava os discípulos", num festival de iguarias como "mãozinha de discípulo em geléia com molho tártaro" ou ainda ao "molho

\footnotetext{
${ }^{60}$ HATHERLY, 2006a, p. 117.

${ }^{61}$ HATHERLY, 2006a, p. 16.

${ }^{62}$ HATHERLY, 2006a, p. 55.
} 
de vinaigrette". ${ }^{63}$ Quando lhe é servida a carne da Discípula, porém, ele não lhe come as mãos, e sim os olhos, "num prato de osso, talvez de marfim. Provavelmente no marfim dos cem vezes trinta e dois dentes da Discípula" ${ }^{64}$ No capítulo VI, em vez do banquete canibalesco, temos uma cena de estrangulamento, em que o Mestre toca o corpo da Discípula não para acariciá-la, mas para torturá-la, numa inversão sádica da atitude erótica: "Entretanto o Mestre vai estrangulando a Discípula, mas todos os mestres estrangulam sempre os seus discípulos de uma maneira ou de outra. Toda aprendizagem é uma forma de estrangulamento de alguma coisa dentro de nós" ${ }^{65}$ A tensão destrutiva entre o Mestre e a Discípula atinge uma dimensão plástica no capítulo IX, que parodia o célebre quadro $A$ lição de anatomia, de Rembrandt (acervo do Mauritshuis, Amsterdã): aqui, porém, é o cadáver do Mestre que se encontra "completamente nu deitado em cima duma mesa de pedra”, onde será estudado por um grupo de estudantes, que passam a

${ }^{63}$ HATHERLY, 2006a, p. 55.

${ }^{64}$ HATHERLY, 2006a, p. 55.

${ }^{65}$ HATHERLY, 2006a, p. 70. O ensino do Mestre não conduz ao amor e à alegria, mas a uma relação de poder em que os discípulos são tragados em um sistema de regras; eles devem se integrar a uma ordem, no qual serão anulados. Esta dimensão política do livro pode ser relacionada ao contexto político de Portugal na época em que o romance foi escrito, quando o país vivia sob o regime ditatorial salazarista. Uma outra caricatura política inserida no romance é a de Lisboa transformada numa cidade-museu: "A Discípula andava a passear à noite por entre as ruínas da cidade que estava transformada em espetáculo para turistas. A Discípula também é turística, turista e cicerone. Vai dizendo: - Meus senhores, olhai à esquerda o rio..." (HATHERLY, 2006a, p. 102-103) Em outras passagens mais explícitas lemos: "Tudo faz parte de tudo, não? De resto, ele agora é o rei das ruínas, ou o rei da cidade em ruínas ou o rei das ruínas da cidade. Está arruinado porque vive das ruínas e nelas. Um rei arruinado e triste. Quando um rei está arruinado, como o não estarão seus vassalos?” (HATHERLY, 2006a, p. 105). O diálogo entre a Discípula (convertida em cicerone) e os turistas sobre a escravidão é ainda mais enfático: “- Somos todos escravos uns dos outros ou de alguma coisa, ao mesmo tempo que se escravizamos sempre alguma coisa ou alguém. Esta é que é a base da liberdade: para que alguém suba, alguém tem de descer. É como se o espaço em cima ou em baixo fosse limitado ou tão matematicamente regulado que uma determinada deslocação num nível tivesse de produzir inevitavelmente uma deslocação compensadora. Deve ser para manter as forças a um nível desejável. - Quais forças? - As forças da destruição" (HATHERLY, 2006a, p. 107). 
ler suas entranhas, nada encontrando além da escuridão (outra metáfora da incomunicabilidade: o corpo do Mestre convertido numa forma de escritura ilegível, um significante sem significado). Esta passagem, de múltiplos significados e camadas de leitura, sintetiza algumas das principais chaves temáticas do romance, presentes ainda em outras obras da autora, e em especial as Tisanas, como a solidão, a impossibilidade do amor e da sabedoria; tudo é um jogo de pedras coloridas num tubo de caleidoscópio, que formam desenhos mutáveis e impermanentes, uma geometria da transformação. Para representar essa visão da instabilidade das coisas e o mal-estar do viver no mundo, regido pela insatisfação, pela divisão interna do indivíduo (representada pela metáfora do Andrógino Potencial, ${ }^{66}$ dividido em três partes) e pelo conflito com a ordem estabelecida, Ana Hatherly atualizou os recursos do barroco em diálogo com as poéticas da vanguarda, numa época em que Portugal se debatia entre a continuação de um regime autoritário já anacrônico na Europa e a saudade de um futuro com dimensões utópicas, que inspiraria a Revolução dos Cravos, em 25 de abril de 1974.

${ }^{66}$ Segundo Silvina Rodrigues Lopes, "a noção de sujeito dividido é fundamental. O confronto de opostos, como constituição / destruição, vida / morte, não se encaminha nesta novela para nenhuma Aufhebung. Nenhuma plenitude é anunciada em O Mestre, embora o desejo de a atingir - a vontade de harmonia, de perfeição ou alegria - seja um dos impulsos dramatizados na novela (...) Qualquer tipo de oposição é desde o início perturbado pelo desdobramento das personagens, dos temas e das situações. Do lado da Discípula, surge uma 'terceira parte do andrógino potencial', que longe de ser o resultado de uma reconciliação / superação é, pelo contrário, uma interferência incontrolada cujo efeito gera inconciliabilidade - do desejo e do seu objeto, do significante e do significado, da vida e da morte". (HATHERLY, 1995, p. 8-9) 


\section{Referências Bibliográficas}

ÁVILA, Affonso: O lúdico e as projeçôes do mundo barroco. São Paulo: Perspectiva, 1994.

HATHERLY, Ana. 463 tisanas. Lisboa: Quimera, $2006 \mathrm{~b}$.

HATHERLY, Ana. O mestre. Rio de Janeiro: Sette Letras, 2006a.

HATHERLY, Ana. Interfaces do olhar. Lisboa: Roma Editora, 2004.

HATHERLY, Ana. A casa das musas. Lisboa: Editorial Estampa, 1995.

HATHERLY, Ana. O mestre. 3. ed. Lisboa: Quimera, 1995.

HATHERLY, Ana. A experiência do prodígio - bases teóricas e antologia de textosvisuais portugueses dos séculos XVII e XVIII. Lisboa. Imprensa Nacional-Casa da Moeda, 1983.

HATHERLY, Ana. O mestre. 2. ed. Lisboa: Moraes Editores, 1976.

HUIZINGA, Joahan. Homo ludens. O jogo como elemento da cultura. São Paulo: Perspectiva, 2007.

\section{Resumo}

O mestre, livro de Ana Hatherly publicado em 1963, é um romance experimental construído numa estrutura similar à dos jogos, com uma ordem, objetivos e regras específicas. Este artigo faz uma análise do caráter lúdico da obra a partir das formulações teóricas de Johan Huizinga.

\section{Abstract}

O mestre, book by Ana Hatherly published in 1963, it is an experimental novel constructed in a structure similar to games, with an order, aims and specific rules. The present article analyses the work's playful feature in the light of the theoretical formulations by Johan Huizinga. 